\title{
The Impact of State-owned Urban Land Leasing on Intention to Reside of Migrant Labors
}

\author{
Mingfeng Jiang ${ }^{1, a}$ \\ ${ }^{1}$ School of Economics, Sichuan University, Chengdu, China
}

\begin{abstract}
Based on the data of the 74310 individual migrant labors from 250 cities that distribute uniformly in China, taking the fiscal stress of the local governments as the instrumental variable due to endogeneity, the IV-probit models indicate that: the area of state-owned urban land leasing promotes the overall intention to reside of migrant labors. Besides, the use structure of urban land leasing matters as well. Land leasing for public service effects the intention to reside positively while land leasing for house building and the secondary industry restrain the intention through mediators like education, house price and industry scale. State-owned urban land leasing for the tertiary industry is proven uncorrelated with the intention to reside, however. It is advised that the local governments ought to choose the urban land leasing structure with larger proportion of land for public service and less proportion of residential and industrial land to strengthen the intention to reside of migrant labors.
\end{abstract}

\section{Introduction}

The mobile population have been one of the major issues worldwide $^{[1]}$ and so are they in China. The Mobile Population Development Report of China 2018 indicates that accounting for nearly one fifth of the country's whole population, the size of the mobile population in China reached 245 million in 2017. At the mean time, the mobile population size in China shrank from 253.53 million to 245 million during 2015-2017 constantly, which implies the growing intention to reside of the mobile population.

As a large proportion in the mobile population, migrant labors are of vital importance for urban development. Researchers have found that migrant labors can be the supplement for the urban labor market based on the evidence in Shanghai (Wang and Shen, $2001)^{[2]}$. The research based on Shanghai also proves that the output elasticity of migrant labors is higher than the residential labors (Yang and Gao, 2012) ${ }^{[3]}$. City administrators have to rely on migrant labors due to the lower birth rate in recent years, to hedge the aggravating negative effect brought about by population aging (Yuan and Jin, 2020 ${ }^{[4]}$. High-quality talents among migrant labors are also of great benefit for independent innovation and industrial upgrading in urban area (Cui and Gao, 2019) ${ }^{[5]}$. In fact, over 50 large or medium cities in China have implemented policies to make migrant labors reside in 2019 .

State-owned land leasing is one of the most active fiscal activities for local governments in China, which can be the base of city construction, industry development and public service supply according to existing researches ${ }^{[6]}$. The research based on the panel data of 36 cities located in the middle reaches of the Yangtze River finds that urban land leasing promotes construction of infrastructure ( $\mathrm{Li}, \mathrm{Gu}$ and $\mathrm{Zhu}, 2020)^{[7]}$. Marketized urban land leasing promotes the green total factor productivity and industrial structure supererogation (Jiang, $\mathrm{Lu}$ and Gong, 2019) ${ }^{[8]}$. Meanwhile, the residing decision of migrant labors lies on the utility of urban life (Bondy, 2020) ${ }^{[9]}$, which is potentially correlated with urban land leasing and the following-up construction. However, this potential correlation has not been of much mention among researches so far.

Based on IV-probit model and statistics from the China Migrant Population Dynamic Monitory Statistics, according to which "reside" is defined as "live for 5 years or longer", the China City Statistical Yearbook and the China Land Resource Yearbook, the conclusion is that state-owned urban land leasing promotes the intention to reside of migrant labors through several mechanisms including house price, public service and industrial scale.

\section{Data source and model setup}

\subsection{Data source}

Individual data of migrant labors come from the China Migrant Population Dynamic Monitory Statistics 2016. It is the annual work of the National Bureau of Statistics and includes a random sample from 31 provinces in

E-mail: ${ }^{a}$ mikejiang_garlic@163.com 
China taking the Probability Proportionate to Size Sampling Method (PPS) to avoid selection bias. Sticking strictly to the national unified standard, the data are superior in veracity, representativeness and scientificalness. Observations with severe data loss rejected, the total sample size is 74310 , among whom there are 38995 individuals from the eastern part of China, and 20331 individuals from the middle part as well as 14984 individuals from the western part.

City data come from the China City Statistical Yearbook and the China Land Resource Yearbook of 2013-2015. Up to now there have been 293 prefecturelevel cities, 15 sub-provincial cities and 4 province-level municipalities in mainland China. Considering the integrity of each variable and the adjustments of administrative division, data from 250 cities are selected into the sample for the empirical analysis eventually. Cities distribute uniformly in China, which makes the sample representative.

\subsection{Variables and endogeneity}

\subsubsection{The explained variable}

The explained variable is the intention of an individual migrant labor to reside in the certain urban area for 5 years or longer according to the survey in 2016 , and " 1 " is assigned to "yes", "0" to "no".

\subsubsection{The explanatory variables}

The core explanatory variable is the total area of stateowned urban land leasing during 2012-2014 of each city considering the interval between land leasing and the utility of the following-up construction.

The control variables include the average house price, the GDP per capita, the proportion of the secondary industry, the proportion of the tertiary industry, the population density, the average wage, the teachers per primary and middle school student, the doctors per capita and other indicators of each city in 2015 to control the proven effects from city economy and employment
(Zhang and Yang, 2020) ${ }^{[10]}$, public service (Xia and Lu, $2015)^{[11]}$ and other factors on the intention to reside.

\subsubsection{Endogeneity and Instrumental Variable}

Considering endogeneity in the probit model, the budgetary fiscal stress of local governments is selected as an instrumental variable(IV), which equals to budgetary expenditure minus budgetary revenue. Existing research shows that state-owned land leasing is a common method for local governments to release their fiscal stress (Zheng, 2020), and the weakiv test aims to prove the correlation between IV and core explanatory variable.

The exclusion restriction is vital for an IV, which means IV effects the explained variable only through the endogenous variable. On one hand, the IV is strongly correlated with budgetary expenditure and budgetary revenue which is included in model residuals. However, budgetary revenue do not have much correlation with the intention to reside because of the little difference in taxation among local governments in China, which means that as tax burden is the most influential proportion in budgetary revenue for individual migrant labor, it ranges slightly among different cities for the same person, turning out to be a trivial factor on intention to reside of migrant labors. Budgetary expenditure does not have much correlation with the intention to reside, neither. Expenditure will not necessarily turn into utility of migrant labors with an inappropriate expenditure structure. On the other hand, the IV does not have much correlation with other control variables. Fiscal stress reveals the necessity for more revenue through land leasing while it does not effect the level of city development indicators so that the IV is not correlated with the control variables, neither. In conclusion, the IV does not violate the exclusion restriction.

\subsubsection{The descriptive statistics}

The descriptive statistics of variables are as table I:

\section{TABLE I. THE DESCRIPTIVE STATISTICS OF VARIABLES}

\begin{tabular}{|c|c|l|l|l|l|l|l|l|l|}
\hline $\begin{array}{c}\text { Variable } \\
\text { Column1 }\end{array}$ & Lable & $\boldsymbol{N}$ & Mean & $\boldsymbol{S d}$. & $\begin{array}{l}\text { Variabe } \\
\text { Column 2 }\end{array}$ & Lable & M & Mean & Sd. \\
\hline res & Intention to Reside & 74310 & 0.568 & 0.495 & wage & $\begin{array}{c}\text { Natural Logarithm to } \\
\text { Average Wage (Yuan) }\end{array}$ & 74310 & 11.030 & 0.179 \\
\hline land & $\begin{array}{c}\text { Area of Urban } \\
\text { Land Leasing } \\
\text { (hm2) }\end{array}$ & 74310 & 7887.301 & 5649.802 & people & $\begin{array}{c}\text { Natural Logarithm to } \\
\text { Population Density (People } \\
\text { per Square Kilometer) }\end{array}$ & 74310 & 6.118 & 0.802 \\
\hline land ind & $\begin{array}{c}\text { Land Leasing for } \\
\text { Industry (hm2) }\end{array}$ & 74310 & 2883.2962397 .736 & house & $\begin{array}{c}\text { Natural Logarithm to } \\
\text { Average House Price (Yuan) }\end{array}$ & 74310 & 8.948 & 0.530 \\
\hline land com & $\begin{array}{c}\text { Land Leasing for } \\
\text { Commerse } \\
\text { (hm2) }\end{array}$ & 74310 & 859.456 & 674.013 & gdpper & $\begin{array}{c}\text { Natural Logarithm to GDP } \\
\text { per Capita (Yuan) }\end{array}$ & 74310 & 11.150 & 0.460 \\
\hline
\end{tabular}




\begin{tabular}{|c|c|c|c|c|c|c|c|c|c|}
\hline land pub & $\begin{array}{c}\text { Land Leasing for } \\
\text { Public Service } \\
(\mathrm{hm} 2)\end{array}$ & 74310 & 1587.461 & 1338.827 & doctor & Doctors per Capita & 74310 & 0.003 & 0.001 \\
\hline land hou & $\begin{array}{l}\text { Land Leasing for } \\
\text { Houses }(\mathrm{hm} 2)\end{array}$ & 74310 & 2172.015 & 2315.096 & teacher & Teachers per Student & 74310 & 0.670 & 0.010 \\
\hline sind & $\begin{array}{l}\text { Proportion of the } \\
\text { Secondary } \\
\text { Industry }(\%)\end{array}$ & 74310 & 45.540 & 8.727 & road & Area of Road $(\mathrm{km} 2)$ & 74310 & 5075 & 4516 \\
\hline tind & $\begin{array}{l}\text { Proportion of the } \\
\text { Tertiary Industry } \\
(\%)\end{array}$ & 74310 & 48.390 & 10.060 & wage & $\begin{array}{l}\text { Natural Logarithm to } \\
\text { Average Wage (Yuan) }\end{array}$ & $74310 \mid$ & 11.030 & 0.179 \\
\hline book & Books per Capita & 74310 & 1.330 & 1.470 & IV & $\begin{array}{c}\text { Instrumental Variable Fiscal } \\
\text { Stress (Yuan) }\end{array}$ & 74310 & 54554 & \\
\hline
\end{tabular}

\subsection{Hypotheses and Models}

\subsubsection{Introduction of IV-probit model}

The probit model is a typical binary selection model. Given that:

$P(y=1 \mid x)=F(x, \beta)$

$P(y=0 \mid x)=1-F(x, \beta)$

$\mathrm{Y}$ is an incident with binary results and $\mathrm{x}$ is a factor that effects $y . \beta$ is the coefficient. $P(y=1 \mid x)$ is the probability for result " $y=1$ ". $F(x, \beta)$ is called the link function. If $\mathrm{F}(\mathrm{x}, \beta)$ is a standard normal cumulative distribution function (CDF), then:

$\mathrm{P}(\mathrm{y}=1 \mid \mathrm{x})=\mathrm{F}(\mathrm{x}, \beta)=\Phi\left(\mathrm{x}^{\prime} \beta\right)=\int_{-\infty}^{\mathrm{x}^{\prime} \beta} \Phi(\mathrm{t}) \mathrm{dt}$

Model (3) is the general form of probit model. $\Phi$ means standard normal distribution. For probit model with endogeneity, the instrumental variable(IV) is necessary to make the estimate consistent. IV-probit model is the probit model with IV. The usual method to construct an IV-probit model is the control function approach. Compared with the multiple linear regression, the IV-probit model is more accurate in depicting binary selection and more effective in avoiding endogeneity.

\subsubsection{Impact of State-owned Urban Land Leasing}

State-owned urban land leasing is the base of the following-up city construction which may promotes utility of migrant labors and their intention to reside eventually. Based on this logical chain, the first hypothesis is as follows:

Hypothesis 1: State-owned urban land leasing effects the intention to reside of migrant labors positively.
Model is set up to test the hypothesis as followed:

$$
\operatorname{probit}\left(\operatorname{res}_{\mathrm{ij}}\right)=\alpha_{0} \operatorname{land}_{\mathrm{j}}+\alpha_{\mathrm{i}} \operatorname{control}_{\mathrm{j}}+\beta_{0}+\operatorname{city}_{\mathrm{j}}+\varepsilon_{\mathrm{ij}}
$$

In (4), the variable res $_{\mathrm{ij}}$ means the intention to reside of the individual migrant labor $\mathrm{i}$ in the city $\mathrm{j}$. The variable land $_{j}$ is the area of land leasing in the city $j$ where the individual i lives currently. The variables control $_{j}$ are the control variables of the city $j$. The constant $\beta_{0}$ is the intercept term. The term city ${ }_{j}$ is the urban fixed effect. The term $\varepsilon_{\mathrm{ij}}$ is the residual. Fiscal stress, which is not displayed in model above, is the instrumental variable for land $_{j}$.

\subsubsection{Mechanism of the Impact}

Urban land leasing may effect the intend to reside of migrant labors through several mechanisms related to some mediators. According to the China Land Resource Yearbook, the land source in China can be classified as industrial land, commercial land, residential land, administration and public services land. Based on the classification, hypotheses are as follows:

Hypothesis 2a: industrial and commercial land effect the intention by expanding industrial scale.

Model is set up to test the hypothesis as followed:

$$
\begin{aligned}
& \operatorname{probit}_{\left(\operatorname{res}_{\mathrm{ij}}\right)=\alpha_{0} \text { ind }_{-} \sec _{\mathrm{j}}+\alpha_{1} \text { land }_{-} \text {ind }_{\mathrm{j}}} \\
& \quad+\alpha_{2} \sin \mathrm{d}_{\mathrm{j}}+\alpha_{\mathrm{i}} \operatorname{control}_{\mathrm{j}}+\beta_{0}+\operatorname{city}_{\mathrm{j}}+\varepsilon_{\mathrm{ij}}
\end{aligned}
$$

$$
\begin{aligned}
& \operatorname{probit}\left(\operatorname{res}_{\mathrm{ij}}\right)=\alpha_{0} \operatorname{com} \_ \text {ter }_{\mathrm{j}}+\alpha_{1} \text { land }_{-} \operatorname{com}_{\mathrm{j}} \\
& +\alpha_{2} \text { tind }_{\mathrm{j}}+\alpha_{\mathrm{i}} \operatorname{control}_{\mathrm{j}}+\beta_{0}+\text { city }_{\mathrm{j}}+\varepsilon_{\mathrm{ij}}
\end{aligned}
$$


In (5), the term ind $\sec _{\mathrm{j}}$ is the cross term of the industrial land leasing land_ind ${ }_{i}$ and the proportion of the secondary industry $\sin \mathrm{d}_{\mathrm{j}}$ set to test the mechanism of industrial land leasing that effects the intention to reside.

In (6), the term com_thi $i_{j}$ is the cross term of the commercial land leasing land_com $\mathrm{j}_{\mathrm{j}}$ and the proportion of the tertiary industry tind $\mathrm{j}_{\mathrm{j}}$ set to test the mechanism of commercial land leasing that effects the intention to reside.

Hypothesis 2b: residential land effects the intention by increasing the house price.

Model is set up to test the hypothesis as followed:

$$
\begin{aligned}
& \operatorname{probit}\left(\operatorname{res}_{\mathrm{ij}}\right)=\alpha_{0} \text { hou_hou }_{\mathrm{j}}+\alpha_{1} \text { land }_{-} \text {hou }_{\mathrm{j}} \\
& \quad+\alpha_{2} \ln _{-} \text {house }_{\mathrm{j}}+\alpha_{\mathrm{i}} \operatorname{control}_{\mathrm{j}}+\beta_{0}+\operatorname{city}_{\mathrm{j}}+\varepsilon_{\mathrm{ij}}
\end{aligned}
$$

In (7), the term hou hou $_{j}$ is the cross term of the residential land leasing land_hou ${ }_{j}$ and the house price $\ln$ house $_{j}$ set to test the mechanism of residential land leasing that effects the intention to reside.

Hypothesis 2c: public service land effects the intention by increasing public service quantity
Model is set up to test the hypothesis as followed:

$$
\begin{aligned}
& \operatorname{probit}\left(\text { res }_{\mathrm{ij}}\right)=\alpha_{0} \mathrm{pub}_{-} \text {tea }_{\mathrm{j}}+\alpha_{1} \text { land }_{-} \mathrm{pub}_{\mathrm{j}} \\
& \quad+\alpha_{2} \text { teacher }_{\mathrm{j}}+\alpha_{\mathrm{i}} \text { control }_{\mathrm{j}}+\beta_{0}+\text { city }_{\mathrm{j}}+\varepsilon_{\mathrm{ij}}
\end{aligned}
$$

In (8), the term pub_tea ${ }_{j}$ is the cross term of the public service land leasing land_pub ${ }_{j}$ and the teachers per student teacher ${ }_{j}$ set to test the mechanism of public service land leasing that effects the intention to reside.

\section{Empirical analysis based on IV- probit model}

\subsection{The Overall Impact of State-owned Urban

\begin{tabular}{|c|c|c|c|}
\hline \multicolumn{4}{|c|}{$\begin{array}{l}\text { Explaned variable: res } \\
\text { Number of observations: } 74310 \\
\text { Instrumental variable: } \text { iv1 (the fiscal stress of the local government) }\end{array}$} \\
\hline land & $\begin{array}{c}0.00145 * * * \\
(0.000)\end{array}$ & unemployment & $\begin{array}{c}0.001 \\
(0.001)\end{array}$ \\
\hline gdpper & $\begin{array}{c}0.198 * * * \\
(0.021)\end{array}$ & teacherper & $\begin{array}{c}5.997 * * * \\
(0.542)\end{array}$ \\
\hline sind & $\begin{array}{c}-0.022 * * * \\
(0.002)\end{array}$ & book & $\begin{array}{c}0.045^{* * *} \\
(0.006)\end{array}$ \\
\hline tind & $\begin{array}{c}-0.016^{* * *} \\
(0.002)\end{array}$ & road & $\begin{array}{c}-0.000 * * \\
(0.000)\end{array}$ \\
\hline house & $\begin{array}{c}-0.266^{* * *} \\
(0.018)\end{array}$ & doctorper & $\begin{array}{c}30.258 * * * \\
(4.975)\end{array}$ \\
\hline wage & $\begin{array}{c}0.166^{* * *} \\
(0.044)\end{array}$ & city effect & $\begin{array}{c}0.122 * * * \\
(0.014)\end{array}$ \\
\hline people & $\begin{array}{c}-0.055^{* * *} \\
(0.009)\end{array}$ & _cons & $\begin{array}{l}-0.072 \\
(0.394)\end{array}$ \\
\hline Wald test of exogeneity & 0.012 & $\begin{array}{l}\text { Anderson-Rubin } \\
\text { test }\end{array}$ & 0.0124 \\
\hline
\end{tabular} Land Leasing}

The result of regression based on (4) is as table II:

TABLE II. THE RESULT OF IV-PROBIT REGRESSION

The instrumental variable in (4) is the fiscal stress of the local government in the certain city. Result of Wald test of exogeneity shows that we can view endogeneity exists in the model at the significance level of $5 \%$ so that the IV is necessary. On the other hand, the result of Anderson-Rubin test indicates that it's reasonable to deem there is no weak IV problem in the model at the significance level of 5\%, which means the IV is valid in the model.

The control variable gdp per capita reflects the overall level of city economic development, which effects the intention to reside positively in accordance 
with the existing researches. Lower city house price is able to cut down the living cost of migrant labors and higher wage raises the level of utility, which effect the intention positively. Public services like education, healthcare, transportation offer additional utility to migrant labors to strengthen their intention to reside.

With the variables mentioned above controlled, the core explanatory variable, area of urban land leasing is positively correlated with the intention to reside at the significance level of $1 \%$. In order to identify the potential causality between urban land leasing and intention to reside, the test of mechanisms where the causality lies is necessary.

\subsection{Test of Mechanisms}

Based on (5), (6), (7), (8), the results of regression are as table III:

\title{
TABLE III. THE RESULTS OF MECHANISMS TEST
}

\begin{abstract}
Explained variable: res
Instrumental variables: $i v 1$, iv $2=i v 1 * \operatorname{sind}$, iv $3=i v 1 *$ tind, iv $4=i v 1 * h o u s e$, iv $5=i v 1 *$ teacher
\end{abstract}

(5)

ind_sec

com_ter

hou_hou

pub_tea

control variables

Obs.

Wald test of exogeneity

Anderson-Rubin test
$-0.0006 * * *$

(0.000)

$-0.000035$

(0.000)

$\begin{array}{cccc} & & \begin{array}{c}-0.00098^{* * *} \\ (0.000)\end{array} & \\ & & & 0.040 * * * \\ & & & (0.014) \\ \text { YES } & \text { YES } & \text { YES } & \text { YES } \\ & \text { Cont. To TABLE III } & & \\ 26399 & 27385 & 57000 & 23060 \\ 0.000 & 0.0006 & 0.000 & 0.0060 \\ & & & \\ 0.000 & 0.0028 & 0.000 & 0.0104\end{array}$

Standard errors are in parenthesis, ${ }^{* * *} \mathrm{p}<0.01,{ }^{* *} \mathrm{p}<0.05,{ }^{*} \mathrm{p}<0.1$

According to the results of Wald test of exogeneity and Anderson-rubin test, it's reasonable to view that endogeneity exists and weak IV problem does not exist at the significance level of $5 \%$ in (5). (6), (7), (8), which proves the validity of the instrumental variables.

Besides area of urban land leasing for industry, commerce, house and public service, all other explanatory variables are all controlled in (5), (6), (7), (8) as in (4), too. As the length limits, their coefficients and standard deviations are not showed in the table. Readers who are interested may ask for these from the author.

In (5), the sample consists of individuals who work in the secondary industry since they are most sensitive towards the alteration of this industry logically, which makes, if it exists, the potential causality easier to identify. The result indicates that the cross term ind_sec effects the intention negatively, which means along with the area of industrial land leasing expanding and the secondary industry being enlarged, the intention to reside of migrant labors goes down correspondingly. Noted that the proportion of the secondary industry has fallen form $46.80 \%$ to $40.50 \%$ during $2010-2017$, the adjustment of industrial structure indicates that the external diseconomies of scale exists in the secondary industry in China. As the secondary industry expands due to land leasing, the marginal benefits shrink because of the extra costs from the oversized industry, which is transmitted to the intention of migrant labors through utility.
In (6), the sample consists of individuals who work in the tertiary industry for the similar reason, while the result indicates that the cross term com ter is not correlated with the intention. Since the proportion of the tertiary industry has not fallen down in recent years, it's reasonable to view that the diseconomies of scale does not exist in the tertiary industry for now. In that case, it's hard to affirm the effect of land leasing on the intention to reside transmitted through utility.

In (7), the sample consists of the individuals that haven't purchase houses in the certain city and are more sensitive to the house price, which helps to make the result easier to observe. The result shows that the cross term hou hou effects the intention to reside positively at the significance level of $1 \%$. Current researches have proven that urban land leasing makes the house price increase significantly (Zhang, 2019) ${ }^{[12]}$, which burdens the migrant labors who have not purchased houses with a higher expected living cost that restrains the intention to reside.

In (8), the sample consists of the individuals that are willing to register their residence in the certain city. Logically, since public service is closely linked to the registration of residence in China, people who are willing to register the residence care more about the public service in the city, which makes the potential causality more obvious. The result indicates that the cross term pub tea effects the intention to reside positively at the significance level of $1 \%$. The expansion 
of the area of public service land leasing boosts the local education, which makes the migrant labors more likely to reside for the better chance that the children they have or will have can receive high quality education.

The results of the IV-probit regression indicate that the hypotheses mentioned above are basically tenable. Among the hypotheses, $2 \mathrm{~b}$ and $2 \mathrm{c}$ are tenable according to the results of regression, while $2 \mathrm{a}$ is half tenable since there no correlation between the commerce land leasing and intention to reside. Hypothesis 1 is tenable based on $2 \mathrm{a}, 2 \mathrm{~b}$ and $2 \mathrm{c}$.

\section{The Conclusions}

Based on the sample consists of 74310 individual migrant labors from 31 provinces in China, the empirical analysis indicates that: firstly, urban land leasing promotes the overall intention to reside of migrant labors positively through several mechanisms. Secondly, public service land leasing effects the intention to reside positively through enriching the local educational resources. Finally, industrial and residential land leasing effects the intention to reside negatively when they enlarge the scale of secondary industry where the diseconomies of scale exists or increase the house price that brings out extra living cost.

It is advised that the local governments ought to pay more attention to the use structure of urban land leasing. To strengthen the intention to reside of migrant labors, larger area of public service land leasing and less area of residential land leasing are desirable. Besides, less industrial land leasing is conductive to promoting the intention to reside in accordance with the current trend of industrial upgrading. The urban land leasing with the well-tuned use structure boosts the overall intention to reside of migrant labors.

\section{Acknowledgement}

This paper is sponsored by the National Innovation and Entrepreneurship Training Program for College Students of Sichuan University (Team Number:T2020108448).

\section{References}

1. Eunmi Chang, Hyun Chin, Jeongwon Lee and Ki-Seon Chung, "More than money: the importance of social exchanges for temporary low-skilled migrant workers' workplace satisfaction," International immigration, vol 58, pp. 143-161, February 2020.

2. G.Wang and J.Shen, "Complementary relationship between non-native and native labor in Shanghai," Population Research, vol. 25, pp. 9-19, January 2001.

3. S.Yang and X.Gao, "The effect of migrant labors on the local economy development," Reform of Economic System, vol. 38, pp. 66-69, November 2012.
4. X.Yuan and N.Jin, "The aging society at the times of negative population growth in China," Journal of Fujian Provincial Committee Party School of CPC, vol. 35, pp. 29-37, March 2020.

5. G.Cui and T.Gao, "The effect of urban specialization, diversity and human capital on the economy of northeast China," Research on Financial and Economics Issues, vol. 42, pp. 121-128, November 2019.

6. Oluwasheyi S. Oladipo, "Migrant workers' remittances and economic growth: a time series analysis," The Journal of Developing Areas,vol. 53, pp. 75-88, April 2020.

7. H.Li, R.Gu and Y.Zhu, "The effect and mechanisms of state-owned land leasing on urban agglomeration in the middle reaches of Yangtze River," Resources and Environment in the Yangtze Basin, vol. 19, pp. 35-43, January 2020.

8. X.Jiang, X.Lu and M.Gong, "Marketized land leasing, industrial structure optimizing and green total factor productivity," China land science, vol. 34, pp. 50-59, May 2019.

9. Assaf.S.Bondy, "From migrant to worker: global unions and temporary labor migration in Asia, by M. Ford. Ithaca. Cornell University Press (ILR Press), 2019," British Journal of Industrial Relations, vol. 58, pp. 476-479, April 2020.

10. Z.Zhang and J.Yang, "Living condition, children education and intention to reside," Modern Finance and Economics-Journal of Tianjin University of Finance and Economics, vol. 40, pp. 84-98, February 2020.

11. Y.Xia and M.Lu, "Empirical analysis about the effect of public service on labor transfer," Management world, vol. 36, pp. 78-90, October 2015.

12. J.Zheng, "Fiscal stress of local governments, income from land transfer and house price-evidence from panel data of 35 cities in China," Macroeconomics, vol. 40. pp, 63-74. February 2020. 